\title{
PENGARUH WAKTU PENAHANAN PADA PERLAKUAN PANAS PASKA PENGELASAN TERHADAP KETANGGUHAN SAMBUNGAN LAS BAJA
}

\author{
Muhamad Fitri $^{1{ }^{1 *}, B^{\prime} \text { Bambang Sukiyono }}{ }^{2}$, Martua Limido Simanjuntak ${ }^{3}$ \\ 1,3Program Studi Teknik Mesin, Fakultas Teknik, Universitas Mercu Buana, Jakarta \\ ${ }^{2}$ Program Studi Teknik Mesin, Fakultas Teknik, Universitas Batam, Kepulauan Riau \\ *E-mail: muhamad.fitri@mercubuana.ac.id
}

\begin{abstract}
ABSTRAK
Salah satu metode pengelasan yang banyak digunakan saat ini karena lebih mudah dalam pengoperasiannya, lebih praktis penggunaannya, dapat digunakan untuk semua posisi pengelasan serta lebih efisien adalah metode pengelasan busur nyala logam terlindung atau disebut juga Shield Metal Arc Welding (SMAW). Pada pengelasan ini, logam induk dan logam pengisi akan mengalami siklus termal yang menimbulkan proses pemanasan dan pendinginan setempat sehingga munculnya tegangan sisa (residual stress) dan distorsi (distortion) pada material. Tegangan sisa ini harus dihilangkan karena mengakibatkan menurunnya sifat-sifat mekanik material. Metode yang paling banyak digunakan adalah cara termal yaitu dengan proses perlakuan panas paska pengelasan atau Post Weld Heat Treatment (PWHT). Keberhasilan Perlakuan panas paska pengelasan dalam menghilangkan tegangan sisa Pada PWHT diantaranya dipengaruhi oleh waktu penahanan (holding time). Penelitian ini bertujuan untuk meneliti Bagaimana pengaruh waktu penahanan pada perlakuan panas, terhadap ketangguhan las Baja. Pada penelitian ini, jenis pengelasan yang digunakan adalah las SMAW, Material yang digunakan adalah baja AISI 4130, Elektroda yang digunakan adalah LB-7018-1 standar aplikasi dan klasifikasi AWS A5.1 E70181. Temperatur penahanan (holding temperature) pengujian adalah $650^{\circ} \mathrm{C}$. Holding time pengujian menggunakan tiga variabel yaitu : 2,5 jam, 4,5 jam, 6,5 jam. Spesimen Pengujian impak dilakukan dengan cara Charpy. Dari penelitian ini diperoleh pengaruh variasi holding time pada holding temperature PWHT terhadap ketangguhan las baja AISI 4130.
\end{abstract}

Kata kunci: SMAW, Charpy, PWHT, Waktu Penahanan.

\section{ABSTRACT}

One of the welding methods that is widely used today because it is easier to operate, more practical in its use, can be used for all welding positions and more efficient is called Shield Metal Arc Welding (SMAW). In this welding, the base metal and filler metal will experience thermal cycles which lead to local heating and cooling processes resulting in residual stress and distortion in the material. This residual stress must be removed because it causes a decrease in the mechanical properties of the material. The most widely used method is the thermal method that is by Post Weld Heat Treatment (PWHT). The success of The post-weld heat treatment in removing residual stresses in PWHT is influenced by the holding time. This study aims to examine the effect of holding time on heat treatment, on the weld toughness of steel. In this study, the type of welding used was SMAW welding, the material used was steel AISI 4130, the electrodes used were LB-7018-1 standard application and AWS classification A5.1 E7018-1. The test holding temperature is $650^{\circ} \mathrm{C}$. The holding time of testing uses three variables, namely: 2.5 hours, 4.5 hours, 6.5 hours. The Impact testing is done by the Charpy method. From this study, the influence of holding time variation on PWHT holding temperature on the weld strength of AISI 4130 steel was obtained.

Keywords: SMAW, Charpy, PWHT, Holding Time. 


\section{PENDAHULUAN}

Pengelasan memiliki peranan penting di dunia konstruksi, industri dan teknologi produksi yang berbahan baku logam. Konstruksi mesin banyak menggunakan teknik pengelasan pada sambungan-sambungannya karena dengan menggunakan teknik pengelasan sambungan menjadi lebih sederhana dan juga ringan serta biaya produksi lebih murah.

Banyak metode pengelasan yang biasa digunakan dalam dunia konstruksi dan industri saat ini. Salah satu metode pengelasan yang banyak digunakan saat ini adalah adalah metode pengelasan busur nyala logam terlindung atau disebut juga Shield Metal Arc Welding (SMAW). Metode ini banyak digunakan karena lebih mudah dalam pengoperasiannya, lebih praktis penggunaannya, dapat digunakan untuk semua posisi pengelasan serta lebih efisien. Namun kualitas hasil pengelasan dipengaruhi oleh tingkat keahlian serta jam terbang operator (welder).

Pengelasan busur nyala logam terlindung (SMAW) yang yang termasuk salah satu las listrik merupakan suatu proses pengelasan yang menggunakan panas untuk mencairkan material induk dan elektroda. Panas tersebut ditimbulkan oleh lompatan ion listrik yang terjadi antara katoda dan anoda (ujung elektroda dan permukaan material yang akan dilas.

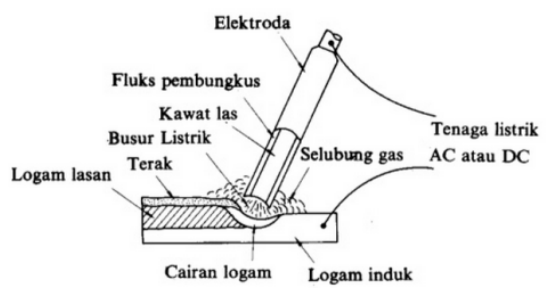

Gambar 1. Las Busur dengan Elektroda Terbungkus [1]

Pada pengelasan, logam induk dan logam pengisi akan mengalami siklus termal yang menimbulkan proses pemanasan dan pendinginan setempat sehingga menyebabkan terjadinya tegangan dan regangan serta mengakibatkan munculnya tegangan sisa (residual stress) dan distorsi (distortion) pada material. Tegangan sisa ini akan mengakibatkan menurunnya sifat-sifat mekanik material. Karenanya tegangan sisa harus dihilangkan. Ada dua cara untuk menghilangkan tegangan sisa, yaitu cara termal atau cara mekanik. Dari kedua metode ini yang paling banyak digunakan adalah cara termal yaitu dengan proses perlakuan panas paska pengelasan atau Post Weld Heat Treatment (PWHT), [1].

$\begin{array}{ccc}\text { Beberapa } & \text { faktor penting } & \text { yang } \\ \text { mempengaruhi } & \text { keberhasilan } & \text { dalam }\end{array}$ menghilangkan tegangan sisa Pada PWHT adalah: laju pemanasan (heating rate), waktu penahanan (holding time), laju pendinginan (cooling rate). Fungsi PWHT, Selain menghilangkan tegangan sisa, juga memperbaiki butir-butir kristal suatu material.

Salah satu parameter yang berpengaruh terhadap sifat mekanis sambungan las adalah Arus pengelasan. Arus pengelasan merupakan parameter las yang langsung mempengaruhi penembusan dan kecepatan pencairan dari logam induk serta elektroda. Makin tinggi arus pengelasan yang digunakan maka makin besar penembusan dan kecepatan pencairannya. Besar arus pengelasan mempengaruhi hasil las, bila arus yang digunakan rendah maka perpindahan cairan dari ujung elektroda yang digunakan akan sangat sulit dan busur listrik yang digunakan tidak stabil. Jika arus yang dipakai besar, maka akan menghasilkan peleburan elektroda yang melebar dan penetrasi dalam serta penguatan matrik las yang tinggi.

Banyak penelitian yang terkait pengaruh kuat arus listrik pengelasan terhadap sifat mekanis sambungan las. Primasta (2017) melakukan penelitian tentang pengaruh jenis elektroda dan kuat arus listrik pengelasan terhadap kekuatan tarik sambungan las SMAW baja ST 37. Dari penelitian tersebut diperoleh : Kuat arus 100 A menggunakan elektroda tipe E6013 mampu mengisi rongga-rongga sudut dengan baik sehingga menghasilkan kekuatan tarik maksimal sebesar 28,81 kgf/mm2, [2].

Widodo EWR dan Suheni (2016) melakukan penelitian terkait Proses pengelasan Stainless Steel AISI 304 metode pengelasan SMAW dengan variasi kuat arus listrik dan jenis kampuh las. Pada penelitian itu diperoleh nilai kekerasan maksimal pada kuat arus 
listrik 130 A dan kampuh las jenis double V, yang mana untuk kekerasan pada daerah logam lasan yaitu $283.99 \mathrm{~kg} / \mathrm{mm} 2$ dan untuk daerah HAZ yaitu sebesar $270.43 \mathrm{~kg} / \mathrm{mm} 2$. Dengan masukan panas (heat input) yang tinggi maka butir yang dibawa akan lebih halus sehingga ketika memadat maka logam lasan menghasilkan kekerasan tinggi, [3].

Prayitno et al. (2018), melakukan penelitian tentang Pengaruh kuat arus listrik pengelasan terhadap kekerasan lapisan lasan baja ASTM A316. Dari penilitian itu diperoleh bahwa: peningkatan arus pengelasan dari 120 A ke 140 A mampu meningkatkan kekerasan dari 465 HV ke 514.7 HV. Namun bila arus listrik pengelasan dinaikkan lagi dari $140 \mathrm{~A}$ ke 160 A akan menurunkan kekerasan dari 51.47 HV ke $423 \mathrm{HV}$, [4].

Santoso et al, melakukan penelitian tentang Pengaruh kuat arus listrik pengelasan terhadap kekuatan tarik dan struktur mikro las SMAW dengan elktroda E7016. Dari penelitian itu diperoleh bahwa Variasi kuat arus pengelasan berpengaruh terhadap nilai kekuatan tarik sambungan las. Kekuatan tarik raw material 36,711 kgf/mm2. Nilai kekuatan tarik dengan kuat arus pengelasan 100 Ampere adalah sebesar $31,863 \mathrm{kgf} / \mathrm{mm} 2$. Sedangkan dengan kuat arus pengelasan 125 Ampere mengalami kenaikan 40,827 kgf/mm2. Kekuatan tarik tertinggi sebesar 48,503 $\mathrm{kgf} / \mathrm{mm} 2$ diperoleh pada pengelasan dengan kuat arus listrik sebesar 150 Ampere, [5].

Dari penelitian-penelitian di atas dapat disimpulkan bahwa kuat arus listrik pengelasan berpengaruh terhadap kekerasan, kekuatan tarik dan struktur mikro logam las. Namun begitu berapa kuat arus listrik yang optimal adalah berbeda beda tiap jenis material. Dan Lagi penelitian-penelitian yang telah disebutkan di atas tidak mengkaji ketangguhan sambungan las. Padahal ketangguhan las merupakan hal yang sangat penting dalam sambungan las. Salah satu cara untuk memningkatkan ketangguhan las adalah dengan melakukan PWHT (Post Weld Heat Treatement). Karenanya pada penelitian ini akan dilakukan penelitian terkait (PWHT).

Penelitian ini bertujuan untuk meneliti Bagaimana pengaruh waktu penahanan pada perlakuan panas, terhadap ketangguhan las
Baja, karena itu maka penelitian ini diberi judul "pengaruh waktu penahanan pada perlakuan panas paska pengelasan terhadap ketangguhan sambungan las baja".

Permasalahan yang diangkat pada penelitian ini adalah meneliti bagaimana pengaruh waktu penahanan pada perlakuan panas paska pengelasan terhadap kekuatan impak sambungan las. Tujuannya adalah untuk mengetahui pengaruh variasi holding time pada holding temperature PWHT terhadap ketangguhan las baja AISI 4130.

Diharapkan dengan penelitian ini diperoleh data waktu penahan yang tepat pada perlakuan panas paska pengelasan (PWHT) agar dapat menghasilkan sambungan las yang tangguh. Sehingga ini bisa menjadi rujukan bagi para praktisi maupun peneliti lainnya yang akan meneliti lebih lanjut tentang ketangguhan las.

Selanjutnya, pada penelitian ini, agar penelitian lebih fokus dan terarah maka dibuat batasan ruang lingkup penelitian ini, yaitu: Jenis pengelasan yang digunakan adalah las SMAW. Material yang digunakan adalah baja AISI 4130. Elektroda yang digunakan adalah LB-7018-1 standar aplikasi dan klasifikasi AWS A5.1 E7018-1, [6]. Temperatur penahanan (holding temperature) pengujian adalah $650^{\circ} \mathrm{C}$. Waktu Penahanan (Holding time) pengujian menggunakan tiga variabel yaitu : 2,5 jam, 4,5 jam, 6,5 jam. Pengujian yang dilakukan adalah uji impak dan dilakukan pada daerah logam las dengan spesimen uji jenis ASTM E23-18, [7].

\section{METODE PENELITIAN}

\subsection{Diagram Alir Penelitian}

Diagram penelitian ini ditunjukkan oleh Gambar 4.1.

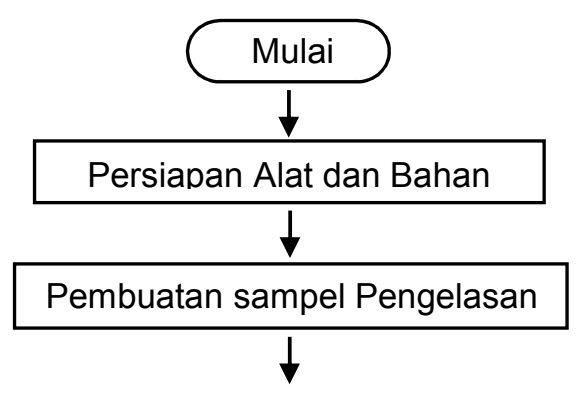




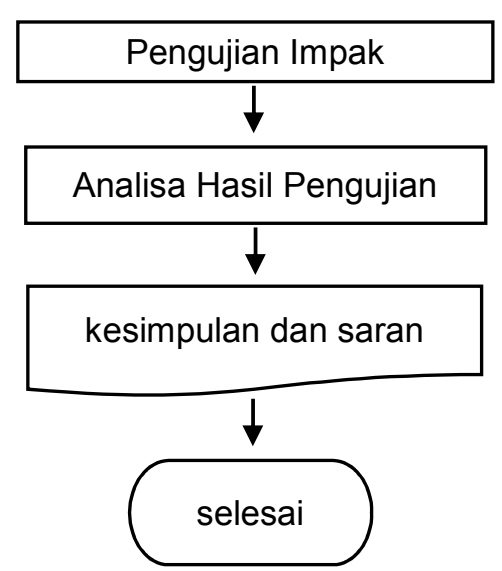

Gambar 2. Flowchart Penelitian

\subsection{Prosedur Penelitian}

Penelitian diawali dengan persiapan alat dan bahan untuk pembuatan sampel pengelasan. Setelah dibuat sampel pengelasan, kemudian dipotong pada daerah sambungan las sesuai standar pengujian impak. Selanjutnya adalah proses pengujian kekerasan impak dengan metode charpy. Hasil pengujian impak dianalisis. Untuk kemudian diambil kesimpulan.

Spesimen uji sendiri disiapkan sebanyak 8 buah. Spesimen holding time 2,5 jam ada 2 buah, spesimen holding time 4,5 jam ada 2 buah, spesimen holding time 6,5 jam ada 2 buah, dan spesimen tanpa PWHT ada 2 buah. Tahapan dalam pembuatan sampel pengelasan adalah sebagai berikut:

a. Tahapan awal adalah pemilihan material yaitu AISI 4130 [8].

b. Tahap kedua dilanjutkan dengan membuat spesimen untuk pengelasan, yaitu pembuatan plat kampuh $\mathrm{V}$ dengan mesin milling seperti terlihat pada Gambar 3.

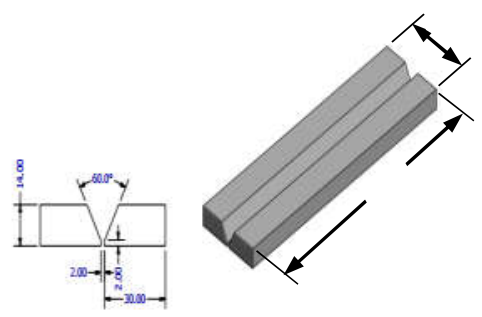

Gambar 3. Plat dengan Kampuh V untuk Pengelasan
Ketika pengelasan SMAW berlangsung, saat elektroda mencair terjadi gas penyelimut, sehingga saat proses ini berjalan diperlukan tekanan / pressure gas inert untuk membuang oksigen atau udara yang dapat menyebabkan korosi atau gelembung-gelembung udara pada hasil pengelasan.

Pada pengelasan SMAW, fluks memegang peranan penting karena fluks dapat bertindak sebagai pemantap busur dan penyebab kelancaran pemindahan butir-butir cairan logam, sumber terak atau gas yang dapat melindungi logam cair terhadap udara di sekitarnya dan sumber unsur-unsur paduan.

c. Kemudian dilanjutkan tahap ketiga yaitu proses pengelasan SMAW. Pada proses ini membutuhkan keahlian dan keterampilan serta jam terbang tinggi, sehingga dilakukan oleh welder berkualifikasi dan tersertifikasi agar hasil pengelasan baik dan sesuai dengan standar.

d. Tahap keempat adalah pembuatan spesimen uji impak. Material yang sudah di las kemudian dibuat menjadi spesimen uji impak sesuai dengan standar pengujian ASTM E23-18 [6] melalui proses permesinan dengan menggunakan mesin milling seperti pada gambar 4 .
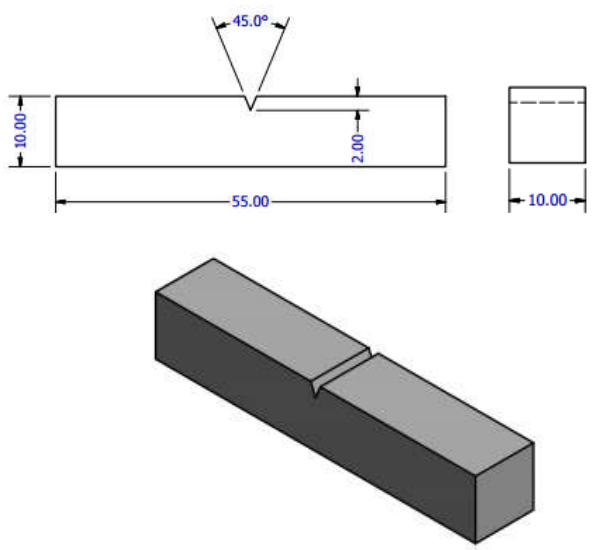

Gambar 4. Spesimen Uji Impak ASTM E2318

e. Tahap kelima yaitu PWHT.

PWHT adalah perlakuan panas yang bertujuan untuk menghilangkan tegangan sisa yang terbentuk setelah proses pengelasan. Akibat pengaruh pengelasan, 
material mengalami perubahan struktur dan butir karena efek siklus pemanasan dan pendinginan yang tidak merata. Struktur dan butir yang tidak homogen ini mengakibatkan terbentuknya tegangan sisa yang membuat material tersebut memiliki sifat kekerasan tinggi namun ketangguhannya rendah. Untuk mengembalikan sifat yang diinginkan terutama dalam ketangguhan maka struktur yang mengalami perubahan tersebut harus melalui suatu proses perlakuan panas pada temperatur tertentu dan dalam jangka waktu tertentu pula yang disebut dengan PWHT. Tergantung dari jenis dan ketebalan material. Secara umum PWHT dilakukan karena alasan seperti:

- Mengurangi tegangan sisa (residual stress).

- Mengurangi kekerasan di daerah pengelasan dan daerah HAZ.

- Meningkatkan ketangguhan (toughness).

- Mengeluarkan hydrogen dari logam las.

- Menghindarkan kerja dingin dari logam.

- Meningkatkan keuletan (ductility).

- Meningkatkan daya tahan terhadap retak karena factor lingkungan (environmental cracking) dan serangan karat.

- Meningkatkan stabilitas dimensional selama machining.

Standar ASME memberikan aturan mengenai batas ketebalan, panas, suhu pendinginan kemudian holding time yang digunakan dalam proses PWHT.

Holding time dilakukan untuk mendapatkan hasil maksimum dari suatu bahan pada proses PWHT dengan menahan pada temperatur yang tertentu guna memperbaiki sifat mekanik yang menurun akibat dari tegangan sisa (residual stress) yang dihasilkan dari proses pengelasan.

Penelitian yang terkait dengan PWHT dilakukan oleh Machmud et al, [9]. Mereka telah melakukan penelitian terkait pengaruh waktu tahan pada perlakuan panas pasca pengelasan terhadap kekerasan dan kekuatan tarik Baja Karbon ASTM A106 grade B. Dari penelitian itu diperoleh bahwa perlakuan panas Normalizing mampu menyeragamkan angka kekerasan di daerah lasan, base metal dan daerah HAZ, yang mana hal ini akan mempengaruhi keuatan tarik dan ketangguhan sambungan las. Namun dalamm penelitian itu tidak membahas tentang pengaruhnya terhadap kekuatan impak spesimen.

Sebelum melakukan proses PWHT, perlu diinspeksi atau diperiksa terlebih dahulu oven yang akan digunakan, untuk memastikan agar saat digunakan dapat berfungsi dengan baik. Kemudian langkah selanjutnya sebagai berikut:

a. Menyiapkan 8 buah spesimen. Dengan rincian holding time 2,5 jam ada 2 buah, holding time 4,5 jam ada 2 buah, holding time 6,5 jam ada 2 buah, dan tanpa PWHT ada 2 buah.

b. Masukkan spesimen untuk perlakuan yang pertama kedalam oven hingga mencapai suhu $650^{\circ} \mathrm{C}$ dan dengan waktu penahanan 2,5 jam. Kemudian didinginkan sampai suhu kamar didalam oven.

c. Mengulangi langkah $b$ dengan waktu penahanan 4,5 jam dan 6,5 jam.

\subsection{Pengujian Sampel dan Pembahasan}

Selanjutnya hasil hasil pengujian impak dimasukkan dalam tabel 1 , untuk kemudian dianalisis agar didapat kesimpulan bagaimana pengaruh waktu penahan pada PWHT terhadap ketangguhan las. Analisis ini dilakukan menggunakan Microsoft Excel untuk membuat persamaan regresi pengaruh waktu penahan terhadap ketangguhan las dari hasil pengujian. Dengan itu maka dapat ditetapkan signifikansi dari pengaruh waktu penahanan pada PWHT terhadap ketangguhan sambungan las.

\section{HASIL DAN PEMBAHASAN}

Data hasil pengujian yang diperlihatkan pada tabel 1 , terlihat bahwa lamanya waktu penahan berpengaruh terhadap kekuatan impak spesimen. Untuk spesimen tanpa waktu penahanan, memiliki Energi impak yang paling rendah yaitu rata-rata sebesar 89 Joule. Hal ini karena tanpa adanya waktu penahanan mengakibatkan temperatur material tidak merata, antara bagian dalam dan bagian luar berbeda jauh. Proses pemulihan tegangan sisa 
nyaris tidak terjadi, kalaupun terjadi tetap tidak efektif.

Tabel 1. Hasil pengujian Impak

\begin{tabular}{ccc}
\hline $\begin{array}{c}\text { Nomor } \\
\text { Sampel }\end{array}$ & $\begin{array}{c}\text { Waktu penahan } \\
\text { (jam) }\end{array}$ & $\begin{array}{c}\text { Energi } \\
\text { impak } \\
\text { (Joule) }\end{array}$ \\
\hline 1 & 0 & 93 \\
2 & 0 & 85 \\
3 & $2,5 \mathrm{jam}$ & 140 \\
4 & $2,5 \mathrm{jam}$ & 137 \\
5 & $4,5 \mathrm{jam}$ & 159 \\
6 & $4,5 \mathrm{jam}$ & 165 \\
7 & $6,5 \mathrm{jam}$ & 167 \\
8 & $6,5 \mathrm{jam}$ & 175 \\
\hline
\end{tabular}

Tabel 2. Rata Rata hasil pengujian impak

\begin{tabular}{ccc}
\hline $\begin{array}{c}\text { Nomor } \\
\text { Sampel }\end{array}$ & $\begin{array}{c}\text { Waktu penahan } \\
\text { (jam) }\end{array}$ & $\begin{array}{c}\text { Energi } \\
\text { impak } \\
\text { (Joule) }\end{array}$ \\
\hline 1 dan 2 & 0 & 89 \\
3 dan 4 & 2,5 & 138,5 \\
5 dan 6 & 4,5 & 162 \\
7 dan 8 & 6,5 & 171 \\
\hline
\end{tabular}

Sedangkan nilai energi impak tertinggi diperoleh pada spesimen dengan waktu penahan sebesar 6,5 jam. Hal ini disebabkan karena dengan penahan waktu yang cukup lama selama 6,5 jam menjadikan temperatur material seragam sehingga proses PWHT berlangsung sempurna dan proses pemulihan tegangan berlangsung secara efektif sehingga ketangguhan material naik.

Selanjutnya, dari data pada tabel 2 digunakan untuk menentukan persamaan regressi polinom orde 2 yang menggambarkan hubungan antara waktu penahan pada PWHT dengan Energi impak sambungan las. Hasilnya diperlihatkan pada gambar 5 .

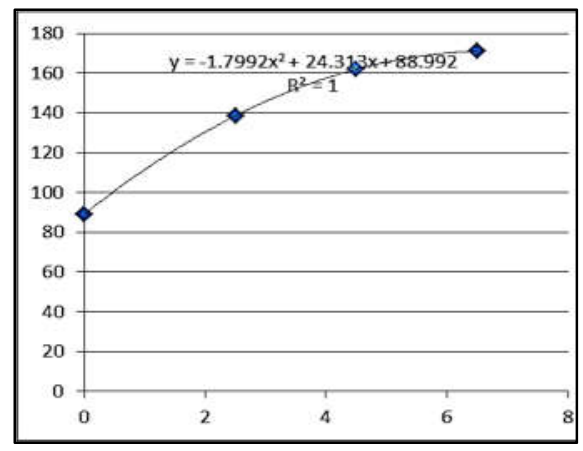

Gambar 5. Kurva regresi hubungan antara Holding Time pada PWHT dengan Energi Impak.
Dari Gambar 4 tampak bahwa persamaan regressi polinom orde 2 untuk hubungan antara holding time pada PWHT dengan Energi Impak adalah:

$Y=-1,7992 X^{2}+24,313 X+88,992$

Dimana:

$\mathrm{X}=$ holding time (jam)

$\mathrm{Y}=$ Energi Impak (Joule)

Dan juga tampak bahwa koefisien determinasi $\left(\mathrm{R}^{2}\right)$ dari hubungan antara holding time pada PWHT dengan Energi Impak adalah 1. Ini artinya hubungannya sangat kuat yaitu 100\% Energi impak dipengaruhi oleh holding time.

\section{KESIMPULAN}

Dari penelitian ini dapat disimpulkan bahwa holding time pada PWHT berpengaruh kuat terhadap ketangguhan las, makin lama holding time makin seragam temperatur material sehingga proses pemulihan tegangan sisa berlangsung lebih sempurna. Akibatnya ketangguhan materal meningkat. Namun itu semua tentunya ada batasnya, terbukti dari grafik regresi terlihat bahw akecenderunyan grafik regresi main lama waktu penahanan grafik cenderung makin mendatar. Artinya, apabila waktu penahan terus ditingkatkan,ada saatnya nanti ketangguhan material tidak meningkat atau bahkan kalau waktu penahan terus menerus ditingkatkan, ketangguhan material malah menjadi makin menurun. Persamaan regresi yang menggambarkan hubungan antara holding time pada PWHT dengan Energi Impak adalah:

$Y=-1,7992 X^{2}+24,313 X+88,992$

Dimana $\mathrm{X}=$ holding time (jam), dan $\mathrm{Y}=$ energi impak (Joule). Koefisien determinasi $\mathrm{R}^{2}$ $=1$.

Mengingat bahwa persamaan regresi yang dihasilkan adalah dalam bentuk persamaan kuadrat, maka untuk mengertahui waktu penahan yang optimum berdasarkan hasil penelitian ini bisa dilakukan dengan menentukan nilai $\mathrm{x}$ pada fungsi turunan dari persamaan regresi untuk $Y=0$. 


\section{DAFTAR PUSTAKA}

[1] Wiryosumarto, H. dan Okumura, T (2004) Teknologim Pengelasan Logam, cetakan kedelapan. PT. Pradnya Paramita,Jakarta.

[2] Primasta, RA, (2017). Pengaruh Kuat Arus Pengelasan dan Jenis Elektroda pada penngujian Tarik Hasil Sambungan Las SMAW pada Baja ST 37, Artikel Skripsi Universitas Nusantara PGRI, Kediri, Indonesia.

[3] Widodo EWR dan Suheni. (2016). Pengaruh Kuat Atus Listrik dan Jenis Kampuh Las terhadap Kekerasan dan Struktur Makro pada Pengelasan Stainless Steel AISI 304. JURNAL iptek VOL 20 No 2. Hal 47-52.

[4] Prayitno D, Hutagalung HD dan Aji DPB. (2018). Pengaruh Kuat Arus Listrik Pengelasan Terhadap Kekerasan Lapisan Lasan Baja ASTM A316. Jurnal Dinamika Vokasional Teknik Mesin. Volume 3 Nomor 1. Hal 1-6.

[5] Santoso TB, Solichin, dan Hutomo PT. (2015). Pengaruh kuat arus listrik pengelasan terhadap kekuatan tarik dan struktur mikro las SMAW dengan elktroda E7016. Jurnal Teknik Mesin. Tahun 23 No 1. Hal 56-64.

[6] AWS A5.1: 2012 (2012), Specification for Carbon Steel Electrodes for Shielded Metal Arc Welding, American Welding Society, United State.

[7] ASTM E23-18, (2018), Standard Test Method for notched bar impact Testing of Metallic Materials : ASTM International, West Coshohocken, PA 2018; Standard volume: 03.01 .

[8] ASM Handbook vol. 1: 148, (1993), Properties and selection: Irons, Steels, and High Performance Alloys, ASM Handbook Committee, United State.

[9] Machmud MN, Maulana D dan Husaini (2013). Pengaruh Waktu Tahan pada Perlakuan Panas Pasca pengelasan terthadap Kekerasan dan Kekuatan Tarik Baja Karbon ASTM A106. Jurnal Teknik Mesin Unsyiah. Volume 1 nomor 3. 